\title{
The Modeling of Social Distance on the Mat: Towards a Semiotic Study of Aikido
}

\author{
Grigor Ghazaryan \\ Yerevan State University
}

\begin{abstract}
The study of language through sign systems that represent "by-products" or substitutes of language as a means of communication is a direction in linguistics that adds to the knowledge about the productivity and language-generating potential of natural languages. Nonverbal language which boasts a plethora of wordless cues through which people communicate, includes postures, gestures, stances, and movements, all of which can be analyzed and explained through the use of the instruments of a semiotic methodology. For instance, the study of signs through the rituals, conventions and overall nonverbal interactions in the diaculture of modern Japanese martial arts, reveals interesting characteristics of the sign language used particularly in Kenjutsu and Aikido. The mentioned martial arts make wide use of nonverbal cues that are characterized by features of indexicality, iconicity and symbolicity, and echo concrete social norms and conventions. Those social conventions are materialized and translated into the setting of trainings through philosophical concepts and ideas.
\end{abstract}

Key words: nonverbal communication, aikido, semiotics, social distance, maai, katana, kata, martial arts, combat language.

\section{Introduction}

It is common knowledge that communication takes place not only through words but through gestures as well. Sets of gestures can assume ritualistic nature, if those are expected to be applied in certain settings. When interaction is limited to kinesics and proxemics according to the norms common to a specific environment, communication becomes largely based on nonverbal acts.

Iconic gestures, many of which are uninterpretable by outside viewers without the accompanying explanation (Clark 2004:179), are amply used in Oriental martial arts. The semiotic analysis of the iconic signs used by Aikido practitioners (commonly called aikidōka) can help reveal the characteristics of the communicative model through which objective reality (or at least attributes and 
conventions pertaining to it) is encoded and translated into the training environment.

In the present paper we will consider such notions as sphericity, distance and space (known as "maai" in Oriental martial arts) as basic tools of translating the notions of social distance into the context and setting of Aikido trainings. Special attention will be paid to the concepts of Center and Sword, as important points of ideological reference, in consideration of the fact that postures, gestures, stances, and movements in Aikido are "drawn" in circles, the "imaginary weapon" being the so-called katana (Japanese sword) which is usually substituted or imitated by hands kept in a position that looks like holding a sword in front of one's own body. In the mentioned context, the forms and exercises designed to develop fighting skills incorporate set combinations of positions and movements which are based on and correspondingly generate a certain perception about interpersonal distance.

\section{Spatial Perceptions through the "Language" of Aikido}

Speaking in general terms about the models used to describe reality in one way or another, Roger Bell points out that the latter "range from pictorial or iconic models, in which there is an evident isomorphism between elements in the model and elements of the reality it represents, to analogue and symbolic models. In analogue models, the isomorphism is less, by virtue of making use of one property of the model to represent a different property of the object, while in symbolic models, the relationship between the "real" object and the model cannot be immediately grasped." (Bell 1976:42). Some models may be interpreted in various ways depending on the diacultural or subcultural affiliation of the subjects.

In Aikido, the mat represents a mini-model of the universe, where multiple interpersonal relationships are modeled on the basis of conflict situations. Conflict or confrontation is mostly conventional in the training environment where physical interaction is realized in a "question-and-answer" or "statement-and-reply" format. In the mentioned process we encounter a number of signs that bespeak a highcontext culture on the one hand, and a close connection with social proxemics on the other. No wonder that many concepts of Aikido are borrowed by social anthropologists to signify tactical and behavioural moves of individuals in their social interactions. Such is the example of randori ${ }^{1}$ which is often discussed as a principle of effective leadership (Baum, Hassinger 2002).

Masters of the mentioned martial art make use of a wide arsenal of tools (signs that can be classified either as indices, icons or symbols) in order to relate the 
details of fighting techniques and "common practices" to a wider context of conflict resolution in social interactions in the synchronic perspective, or to ancient fighting practices in the diachronic perspective ${ }^{2}$, and to religious-ideological concepts of Shinto ${ }^{3}$, in the panchronic perspective. Unlike other forms of art, here the use of the mentioned types of signs has not only an aesthetic but also a didactic purpose. In other words, it helps to transmit the message from master to students through tacit forms of communication and through patterned forms known as the "kata". Here we deal with such means of constructing the communicative event as iconic body gestures, and emblems in hand movements that demonstrate the nature and intensity of the physical interaction during the combat. When looking at those models of signaling, "language" must be taken broader than "a language". At least in the notion of "language use" it must include every method by which one person means something for another - describing, indicating, and demonstrating regardless of the instrument used - voice, hands, arms, face, eyes, or body (Clark 2004:188).

Nonverbal cues, often used to invite the opponent to the mat, or the initial postures signifying readiness and alertness, are clear examples of indices. Iconic signs can be noticed in situations in which the practitioner's hands imitate the Japanese sword (katana), whereas symbols can be found in concepts relating, for example, to hierarchy on the vertical axis, and to integrity and personal space on the horizontal axis. The latter is explained on the basis of the concept of "hara" (Center of man and universe at the same time). The use of all these notions in verbal and nonverbal discourse during training sessions comes to characterize the communicative model of Aikido as being complementarily pictorial and symbolic at the same time.

When talking about iconicity and symbolicity in language models such subcategories of the study of nonverbal communication as proxemics (use of space) along with haptics (touch), kinesics (body movement), vocalics (paralanguage), and chronemics (structure of time) should be taken into consideration as important levels of analysis (Moore 2010). The consideration of the mentioned subcategories can be especially effective when analyzing human conventional interactions during martial arts trainings and also when studying the interrelatedness of interpersonal behavioral patterns used in Aikido, as well as those translated into the social setting.

Edward T. Hall, who coined the term proxemics in 1963, emphasized the impact of proxemic behavior on interpersonal communication. Analyzing the 
communicative events of Aikido one may assume that the notions suggested in proxemics could be effective in evaluating the interrelatedness and mutual impact of how people interact and how they organize and use the space around themselves (Hall would mention "the organization of space in [their] houses and buildings, and ultimately the layout of [their] towns" (Hall 1963:1003-1026) which equally applies to the organization of space in an Aikido dojo (training hall)). However, in order to take this argument one step further we would need to look into the results of a separate research works on the effects of sports' diaculture on family and daily life habits.

According to the ideology of Aikido, the whole universe revolves around a center, where the center is the man. This understanding governs the proxemic behaviour of individuals on the mat. "Center and centralization are among the most important notions in Aikido, the consciousness of which is developed through special exercises by the help of which centralization becomes "an accomplished fact referring to the unconscious maintenance of balance - both mental and physical, extension of energy, circularity of motion and action, etc." (Westbrook \& Ratti 2004:104). Circles around the center are "drawn" by movements of the body and hands, usually substituting a weapon.

The concepts of "weapon-hand" (reflected in the understanding of "te katana", which literally means "hand sword") and distance (known as "maai") are fundamental elements of Aikido proxemics. Maai is understood as a spatiotemporal "interval" between two opponents during combat; it formally represents the "engagement distance". When the distance measures about two metres between the opponents, from which either need only one step in order to strike the other, we deal with a setting where techniques (consequently, contact /“conversation") can be initiated. Hence, it becomes clear that in Aikido the distance between personal and social spheres is measured by the length of the sword which is perceived as an extension of human body. The tip of the extended sword is the point which draws the radius of the circle around the person's Self and represents his Ego or the Personal. This is why battle (which in broader

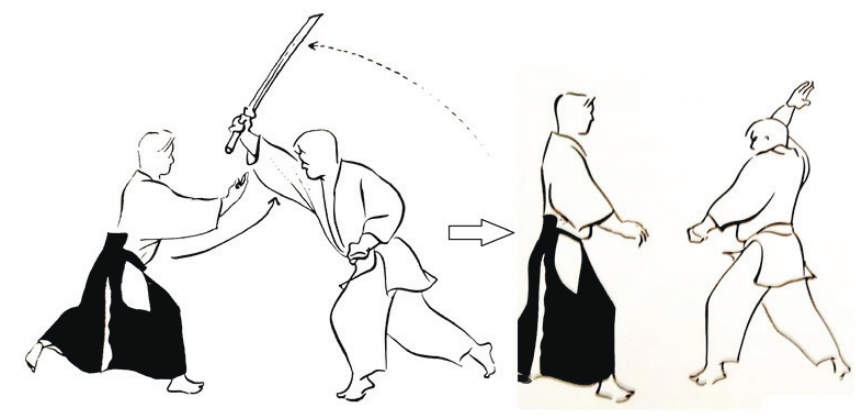


terms can be described as conflict or confrontation) starts when the tips of the opponents' swords cross - they violate each other's personal space.

The use of weapons in general and the use of hands as substitutes of weapons in particular, are largely based on imitation. This makes the discussion about the nonverbal and iconic character of combat language almost inevitable. Moreover, nowadays Aikido is often explained in rather far-reaching abstractions, in which we often come across comparisons between physical contact and dialogue ${ }^{4}$ where the contact between the opponents is seen as a type of conversation ${ }^{5}$ realized through targeted and intentional gestures. If symbolic models of language have the disadvantage for the student, at least, of being much more abstract than the "reality" they are designed to describe and explain, the model of the combat language applied in Aikido is comparatively more iconic, since the gestures it uses as carriers of messages, are based on imitating analogous gestures that pre-existed the bare hand fighting techniques, due to the use of certain elements like weapons, pieces of armour and protective devices (Bell 1976:44).

Another concept essentially related to proxemics is that of sphericity which is pervasive in the ideology of Aikido. It conceptually underlies the division of space into circles around the individual's center and the circularity of motions in the given martial art. Even the employment of katana, by the very logic of its design and structure, is based more upon the circular slash than upon the direct thrust (Westbrook \& Ratti 2004:95).

The dimensions of the concept of centralization range from the cosmic or universal where the Center is identified with the idea of order, harmony, and total integration in the balance of opposites, to the human and personal, where it is seen as the balance point of human personality, the unified basis of individuality and particular character.

With the concepts of center and sphericity in mind, we can notice that social distance in Aikido corresponds to the sphere of objectivity which is literally outside the reach of the

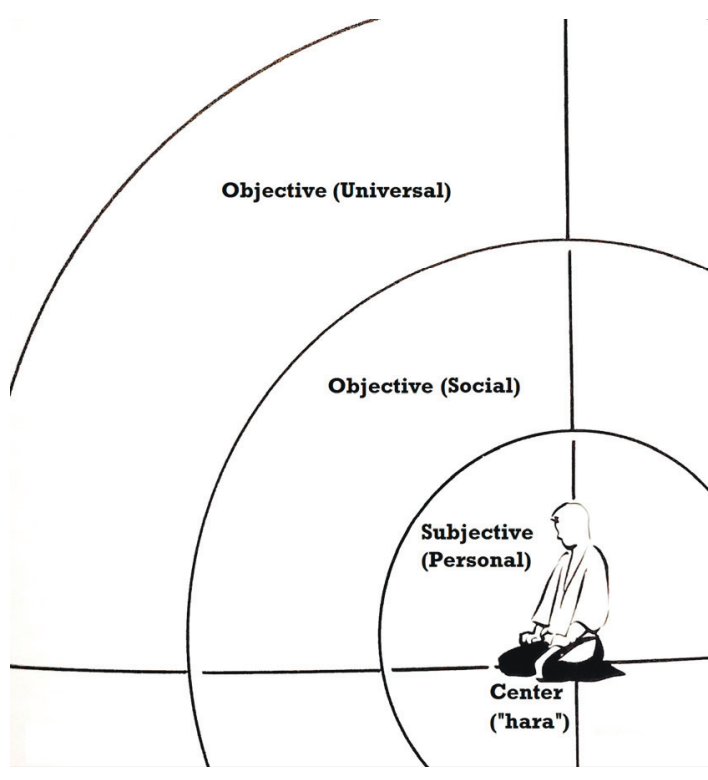


individual's hand (=sword). The cosmic and the human dimensions of the concept of center are closely intertwined, man being an integral part of creation. This refers to the concept of individual integrity, since the Center, according to Eastern philosophy, is all-encompassing and "it is the same for both the general and the particular, for the universe and for man. [...] Separation of man from that identity with the universe, alienation of man from man, and finally, a man's feeling of a split within himself are considered to be the result of paying too much attention to the surface differences, to the details of life. This completely ignores the underlying identity of all life, the basic "oneness" of its essence" (Westbrook \& Ratti 2004:70).

In conformity with the same principle of oneness, the bare hand becomes an iconic image of the Japanese sword (katana) which determines the personal distance and delineates the subjective from the objective (social, and universal). At the same time, conflict is literally understood as the violation of the mentioned personal zone, and conversely, the respect of the personal zone guarantees absence of violence, but also absence of contact, conversation and communication.

\section{hand $<=$ [iconic representation] $=>$ sword $<=$ [symbolic representation] $=>$ distance /maai* \\ $(*$ distance $=$ guarantee of security; absence of confrontation; mutual respect $)$}

As shown above, the hand of an aikidoka iconically stands for the sword, and symbolically represents the distance which is essential to avoiding conflict. The concept of "maai", which incorporates "not just the distance between opponents [proxemics], but also the time [chronemics] it will take to cross the distance, angle and rhythm of attack [kinesics and haptics]" (Jones 2005) helps to get a better understanding of nonverbal communication in Aikido and to read and understand conflict situations from the point of view of Aikido proxemics. As long as any reading of social, real-life situations is based on signs ${ }^{6}$, those readings will accumulate in the process of cognition to form the basis of patterned approaches that are meant to be respectively applied in situations outside the training environment.

\section{Conclusion}

The interaction between Aikido practitioners in the setting of trainings can be seen in terms of a conversation taking place according to pre-set norms and 
through the use of nonverbal linguistic means. The latter are applied by "speakers" (aikidoka) who represent what they mean in symbols which they intend their addressees to interpret using a shared system of sign language.

Similar to a type of conversation, a conventional fight scene (kata) in Aikido implies inherent meanings of breaking and reestablishing balance - initiating and ending a conflict respectively - conveyed through body language (kinesics) and the physical distance between the communicators (proxemics).

Aikido practitioners, taken as speakers, enter into a conversation presupposing a certain common ground where the delineation between personal and social space is marked by emblematic hand gestures which iconically stand for sword movements. The patterned exercises known as the katas, imply certain isomorphism between elements in the model (hands) and elements of the reality (sword) that they refer to. If the general approach of constructing those models is quite iconic or pictorial for the practitioners of Aikido, it appears to be symbolic to outsiders who usually need additional explanation of the nonverbal communicative events discussed above.

\section{Notes:}

1. "The term randori does not translate nicely into English, but it is usually translated loosely as free play. Ran literally means "disorder", "chaos" or "random". Dori does not translate well, but it means to "take hold of". The disorder and randomness of randori was in contrast with the very formal and orderly kata (pre-arranged patterns of technique). Using terms that referred to chaos and randomness clearly set randori as the opposite side of the coin in comparison to traditional kata." (Rego 2014)

2. Founder of Aikido Morihei Ueshiba was said to have studied several different styles of Kenjutsu (Japanese swordsmanship). There are details of Ueshiba's training in those classical martial arts and their influence on the development of modern Aikido. Sword techniques (Aiki-ken) in particular, which became the foundation of Aikido are predominantly based upon the teachings of the ancient fighting techniques of Kashima Shintō-ryu. (Skoss 1993)

3. The ideology of Shinto was intertwined with that of the Ōmoto-kyō movement to which the founder of Aikido Morihei Ueshiba joined in 1919.

4. "Aikido is neither a sport, nor a competition. It is an art of communication among people. There are no winners or losers here. We should forget the approach which is based on an idea like "I am the winner and I am the good and 
you are the loser, and that means you are bad." Aikido contains martial elements, but the accent is laid in interaction. Aikido is a dialogue. I attack and you respond and vice-versa. The attacker and the person being attacked are not looking for a conflict. The aim is to train and not to destroy on another. That is how communication and development take place." (Svyatokhina 2014)

5. "Physical altercation, controlled or uncontrolled, is nonetheless a form of communication that reveals much about an individual's psychological makeup. As such, karate kumite, aikido randori, and kendo or judo shiai, represent nothing more than physical "conversations." If you watch closely, regardless of the art being practiced, you will learn much about any participant's personal style of, or approach to conflict resolution." (Jones 2005)

6. We can see this from Peirce's early idea that every interpretant is itself a further sign of the signified object. Since interpretants are the interpreting thoughts we have of signifying relations, and these interpreting thoughts are themselves signs, it seems to be a straight-forward consequence that all thoughts are signs, or as Peirce calls them "thought-signs" (Peirce's Theory of Signs // Stanford Encyclopedia of Philosophy 2010).

\section{References:}

1. Baum, D.; Hassinger, J. (2002) The Randori Principles: The Path of Effortless Leadership. Chicago: Dearborn Trade Publishing.

2. Bell, R.T. (1976) Sociolinguistics. Goals, Approaches and Problems. NY: St. Martin's Press Inc.

3. Burgoon, J.K.; Guerrero, L.K; Floyd, K. (1996) Nonverbal Communication. NY: Pearson Publishing.

4. (2011) Changing Minds, 10 Apr./6 Dec. 2011. Available at: $<$ http://www.changingminds.org $>$ [Accessed August 2016].

5. Clark, H.H. (2004) Using Language. Cambridge: CUP

6. Hall, Ed.T. (1963) A System for the Notation of Proxemic Behavior. // American Anthropologist 65 (5), pp.1003-1026.

7. Hall, Ed.T. (1969) The Hidden Dimensions. NY: Ancor Books.

8. Jones, T.D. (2005) Angular Attack Theory: An Aikido Perspective. // Aikido Journal. Available at: $<$ http://members.aikidojournal.com/public/angular-attacktheory-an-aikido-perspective $>$ [Accessed August 2016]. 
9. Moore, N. (2010) Nonverbal Communication: Studies and Applications. NY: OUP.

10. (2010) Peirce's Theory of Signs // Stanford Encyclopedia of Philosophy. Available at: <http://plato.stanford.edu/entries/peirce-semiotics/\#SigEleSig > [Accessed August 2016].

11. Skoss, M. (1993) Kashima Shinto-ryu. The Classical Martial Arts Resource. $<\mathrm{http}$ ://www.koryu.com/library/mskoss3.html > [Accessed August 2016]

12. Rego, G. (2014) Randori in Jukido Jujitsu. A Brief Explaination of the History, Development, \& Benefits of Randori in Jukido Jujitsu, Available at: $<\mathrm{http}$ ://www.floridajukido.com/resources/postings/103-randori-in-jukidojujitsu.html $>$ [Accessed August 2016].

13. Svyatokhina, D. (2014) Interview with Takashi Kuroki Sensei, "Yaponskij master aikido podderzhal kollegu iz Bashkirii". "/ Obshestvennaya elektronnaya gazeta. Available at: <http://i-gazeta.com/news/mesta_interesa/ 31725.html> [Accessed August 2016].

14. Westbrook, A.; Ratti, O. (2004) Aikido and the Dynamic Sphere, Boston: Tuttle Publishing.

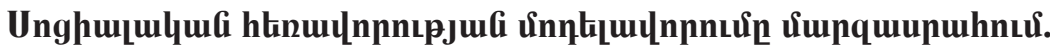

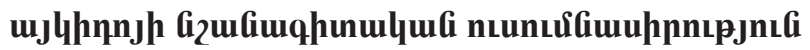

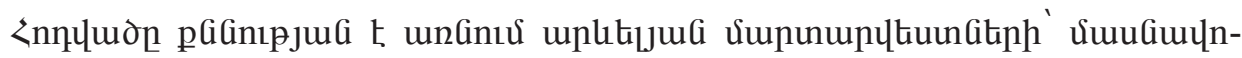

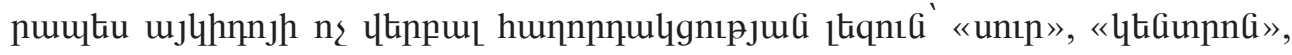

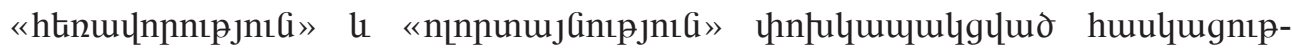

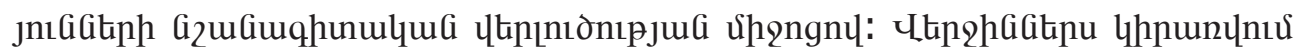

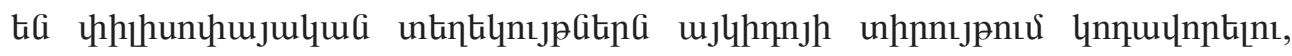

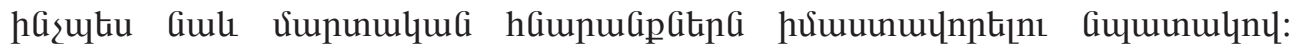

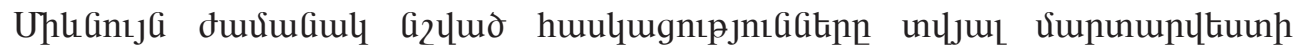

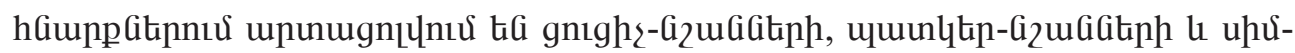

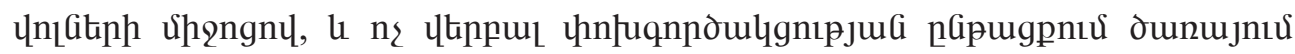

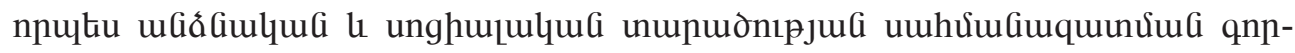

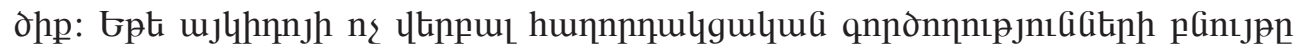

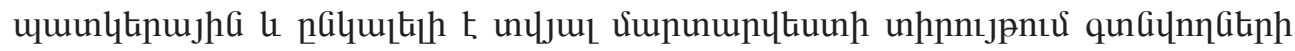

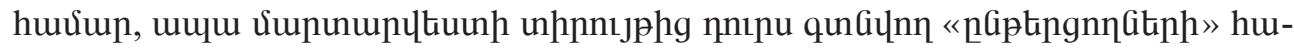

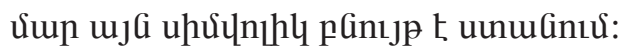

